\title{
Conferencia sobre la Carta Europea de Autonomía Local. (Barcelona, 23-25 de enero de 1992) Por un sistema de control de la Carta Europea de Autonomía Local *
}

\author{
Joaquín Tornos Mas \\ Catedrático de Derecho Administrativo \\ Universidad de Barcelona
}

I. La Carta Europea de Autonomía Local (CEAL) se aprobó introduciendo en su articulado un débil sistema de garantía. El artículo 14 del texto normativo se limita a imponer a las partes contratantes la obligación de suministrar al Secretario General del Consejo de Europa toda la información relativa a la normativa interna que se adopta con el fin de adecuarse a la Carta.

La garantía de la fuerza normativa de la Carta queda así remitida a los mecanismos estatales internos, en la medida que el texto de la Carta pasa a formar parte de los ordenamientos de las partes contratantes, y a los instrumentos propios de las normas generales del derecho internacional. No nos corresponde reflexionar sobre estos aspectos, pues el esfuerzo que se nos pide va dirigido a tratar de encontrar otros cauces que puedan abrirse para hacer más eficaz el contenido dispositivo del texto de la CEAL. Esta es la cuestión, cómo hacer eficaz la CEAL, cómo garantizar que las disposiciones internas de los Estados firmantes no van a contradecir los principios de la Carta.

Reformulamos por tanto el título de la presente sesión. Lo que importa no es controlar la CEAL, sino la defensa de esta norma. Hacer de la misma una verdadera "Constitución de la autonomía local», arbitrando para ello los mecanismos de control sobre la normativa de los Estados, es decir, instituyendo la posibilidad de conocer lo que hacen los Estados y en su caso adoptar la correspondiente medida.

\footnotetext{
* Texto de la Ponencia presentada en la "Conferencia sobre la Carta Europea de Autonomía local" celebrada en Barcelona los días 23 a 25 de enero de 1992, organizada por el Consejo de Europa, Ayuntamiento de Barcelona y el Consejo General del Poder Judicial.
} 
Planteada la cuestión en estos términos, la búsqueda de un mecanismo que garantice la eficacia de la CEAL exige conocer el origen de la misma y su naturaleza. Y ello es así, porque si bien es cierto que diversas Convenciones firmadas en el marco del Consejo de Europa establecen formas de garantía de su contenido, cada una de estas técnicas deben adecuarse a las características propias del texto cuyo contenido tratan de garantizar ${ }^{1}$.

Ya en sus orígenes, debe recordarse que en 1957 la Conferencia de Poderes locales, en su Dictamen 6/1957 sobre la defensa de la autonomía local, sugirió dos formas posibles para garantizar dicha autonomía: una Convención europea especial, o bien la inclusión de un protocolo adicional a la Convención europea de protección de los derechos humanos. El Comité de Ministros rechazó la segunda opción al entender que en la Convención de derechos humanos únicamente tenían cabida los derechos individuales pero no los colectivos. Argumento este discutible (así se refleja en las consideraciones de la Conferencia en su Dictamen posterior 15/1962), pero que llevó a que en su día se decidiera finalmente crear un instrumento jurídico especial para proteger la autonomía local, hecho que está en el origen de la actual Carta Europea de Autonomía local.

Los problemas para llegar a la aprobación de la Carta continuaron. Al elevarse al Consejo de Ministros la Declaración de Principios sobre la Autonomía local en 1968 éste paralizó de hecho la iniciativa hasta 1979 , aduciendo que debían tenerse en cuenta «las diferencias notables que presentan las estructuras constitucionales, jurídicas y administrativas de los diversos Estados miembros del Consejo de Europa".

Se llega así a la aprobación de la CEAL como Convenio abierto a la firma y ratificación de los Estados miembros, introduciendo en su articulado un procedimiento de control que se aparta, por citar dos ejemplos relevantes, del modelo de la Carta Social y más aún de las garantías jurisdiccionales que establece el Convenio sobre derechos humanos ${ }^{2}$. El mecanismo del artículo 14 carece de toda fuerza relevante, pues se limita a exigir el envío de los textos normativos aprobados, sin añadir medida alguna que estimara pertinente el órgano de fiscalización después de haber procedido al estudio de los textos remitidos. Como se ha

\footnotetext{
${ }^{1} \mathrm{Al}$ respecto, vid. CLOTET I MIRO, M.A.: La cooperació internacional dels municipis en el marc del Consell d'Europa, Barcelona 1991, pág. 179 y ss. y GALINSOGA-BLANC-NOVELL. La Autonomía local en el marco jurídico-internacional europeo, "Revista de Estudios de Administración local y Autonómica», 237, 1988, pág. 881 y ss.
}

2 GALINSOGA-BLANC-NOVELL. op. cit., pág. 888. 
CRONICAS

dicho, la justificación de esta limitación puede proporcionarla un argumento avanzado por el propio Sr. Harmegnies, el cual indicó que frente a la Carta Social -que se dirige a garantizar derechos sociales y económicos subjetivos- la autonomía local es una materia que afecta a las relaciones entre autoridades públicas y, por lo tanto, a la propia estructura del Estado ${ }^{3}$. En definitiva, añadimos nosotros, mientras la Convención de Derechos Humanos o la Carta Social hacen posible el control de actos de las autoridades internas de los Estados lesivos de derechos individuales, la creación de una Carta sobre la Autonomía local que actuara como verdadera supra-constitución en esta materia, permitiría cuestionar la legislación interna en un tema que incide directamente en la distribución del poder político sobre el territorio.

Lo expuesto debe tenerse presente a la hora de diseñar un sistema de garantías que sea aceptado y, por tanto, eficaz. Por otra parte, y con este mismo objetivo, debe también tenerse presente que la CEAL es un texto normativo de carácter principal que trata de configurarse como "Constitución" de la autonomía local. Esta característica implica que su contenido vinculará a los legisladores estatales, por lo que todo intento de imponer una garantía "fuerte» de la CEAL supondría admitir alguna forma de mecanismo de anulación de las leyes estatales. Como difícilmente ello será admitido por los Estados, los mecanismos de garantía de la CEAL deben tratar de buscarse a través de fórmulas con las que se consiga la imposición del contenido de la Carta merced a la autoridad técnica de órganos independientes, los cuales fiscalizan y enjuician la conducta de los Estados miembros a través de informes previos y denuncias a posteriori.

II. Antes de proceder a esbozar alguna solución para reforzar la garantía de la CEAL, parece conveniente descartar aquellos mecanismos que, pese a su fuerza, no parecen adecuados al supuesto concreto que estamos examinando.

Uno de los mecanismos ya ha sido apuntado. Me refiero a la posibilidad de establecer una garantía jurisdiccional como la existente en la Convención de Derechos Humanos, ya fuera creando un nuevo Tribunal o bien a través de la inclusión de un Protocolo adicional a la Convención europea de protección de Derechos Humanos. Pese a la fuerza de este mecanismo, por las razones antes expuestas no nos parece aconsejable ni factible.

3 Citado por GALINSOGA-BLANC-NOVELL. op. cit., pág. 889. Las palabras del Sr. HARMEGNIES se encuentran en CONSEIL DE L'EUROPE CPLRE. Rapport sur les Principes de l'Autonomie Locale, 21 de septiembre de 1981. 
Otra fórmula, apuntada en alguna ocasión, podría ser la de tratar de conseguir que la Comunidad Europea reconociera la CEAL como derecho comunitario y garantizara con sus medios la eficacia de este ordenamiento ${ }^{4}$. Pero esta fórmula plantea otros inconvenientes. Por un lado nos encontramos con el límite jurídico infranqueable de que el Tratado de Roma no atribuye a la Comunidad competencias en materia de organización interior ni por tanto de régimen local. Por otro lado existe un problema práctico muy significativo. El ordenamiento jurídico comunitario únicamente vincularía a los miembros de la Comunidad, y estos son muchos menos de los que integran el Consejo de Europa. Y además, seguramente, los países de la Comunidad son los que en mayor medida ya han adecuado su ordenamiento al contenido de la CEAL.

III. ¿Qué solución cabe apuntar? Veamos, pues, ya, qué mecanismos en el marco institucional del Consejo de Europa y atendiendo al contenido de la propia CEAL, pueden apuntarse con el objetivo final de articular una fórmula efectiva a la vez que pragmática de garantía de los principios contenidos en la Carta.

A. Garantía preventiva. Puede apuntarse como una primera forma de imponer la eficacia de la CEAL el condicionar la admisión de nuevos miembros en el Consejo de Europa a la aceptación por los mismos de los principios que configuran dicha Carta.

Para conseguir este objetivo basta con acudir a lo dispuesto en el Estatuto del Consejo de Europa de 5 de mayo de 1949. En su artículo cuarto se establece que los Estados europeos pueden ingresar en el Consejo de Europa si son invitados por el Comité de Ministros y respetan los principios informadores del Consejo. Principios que el artículo tercero reduce a dos: defensa del imperio del derecho y respeto interno a los derechos humanos y libertades fundamentales. Además de poseer estas características propias, se exigirá a los candidatos al ingreso la adhesión a los fines propios del Consejo y la manifestación de voluntad de cooperar a su implantación (artículo primero).

En consecuencia, el ingreso en el Consejo de Europa exige demostrar la posibilidad de homologar la estructura jurídica interna del Estado que solicita su ingreso con los principios que informan del Consejo de Europa y afirmar una voluntad de cooperación en el logro de los fines que son propios de esta institución.

\footnotetext{
4 En este sentido Rapport de Mr. John MORGAN en «Les effectes de l'achèvement du marché intérieur sur l'autonomie locale et régionale» Strasbourg 1990, pág 13.
} 
CRONICAS

Entre estos principios que configuran al Consejo de Europa deberían situarse los contenidos en la CEAL. De este modo, el ingreso de un nuevo miembro podría condicionarse a la acreditación de que respeta el contenido de la Carta. Basta para ello que el Comité de Ministros decida tomar en consideración esta posibilidad y la ponga en práctica. Es decir, se trata de integrar el contenido de la CEAL en el «ordenamiento" propio del Consejo de Europa.

La justificación de esta exigencia puede encontrarse en el argumento de que la autonomía local es una institución que está en la base misma de una estructura democrática del poder, al tiempo que la existencia de niveles de administración local dotados de autonomía política cualificada permiten un mayor desarrollo del ejercicio del derecho de participación política de los ciudadanos.

Por otro lado, la exigencia de la homologación de la legislación de los Estados en materia de régimen local puede compensarse con el apoyo que ofrezca el propio Consejo de Europa o alguno de los órganos, informando y asesorando en materia de legislación local a los Estados que deseen integrarse en el mismo.

B. Garantía en relación a los Estados miembros.

La defensa de la Carta en relación a los Estados miembros del Consejo de Europa y firmantes de la Convención podría reforzarse de modo sustancial a través de la incorporación de un Protocolo adicional en el que se crearan dos nuevos órganos: un Comité Permanente y un Comité de Expertos.

a. El Comité Permanente estaría formado por un representante de cada uno de los Estados que han ratificado la Carta, y al mismo se podrían encomendar las siguientes funciones:

1. Recibir y reclamar informes en relación a los Proyectos de leyes estatales y regionales en materia de autonomía local o que incidan de modo directo y sustancial en el contenido de la misma.

A la vista de los textos recibidos el Comité podría realizar dos tipos de actuación complementarias:

1.a. Emitir un Informe sobre algún Proyecto examinado cuando estimara que pudiera suponer un grave ataque a los principios de la Carta. Dicho Informe se acompañaría de las recomendaciones concretas dirigidas al Estado miem- 
bro para orientar la corrección del Proyecto normativo analizado.

1.b. Elaboración de un Informe anual valorando de modo global y en relación a cada Estado los textos examinados por lo que se refiere a su adecuación a la Carta.

2. Emitir Dictamen a instancia de alguno de los Estados que han ratificado la Carta o que desean incorporarse al Consejo de Europa, en relación a la interpretación que deba darse a la CEAL o en relación a un Proyecto de Ley concreto que se presenta para ser enjuiciado por su conformidad o no con la CEAL.

3. Proponer las reformas que se estimen oportunas en el contenido de la Carta.

b. El Comité de Expertos podría estar compuesto por 5 ó 7 miembros 5 elegidos por el Comité de Ministros sobre la base de una lista de nombres propuestos por la Asamblea Parlamentaria, después de consultar a la CPLRE.

Estos miembros no podrían ser revocados libremente durante el período de su mandato ( 4 a 6 años) y tampoco reelegidos. El acierto en la selección de las personas y la garantía de independencia son determinantes para la eficacia del Comité de Expertos.

Este Comité, a diferencia del anterior, actuará siempre a instancia de parte, y sólo podrán dirigirse al mismo las Asociaciones Municipales más representativas de los diversos países. Cabría también arbitrar la posibilidad de que se admitiera la legitimación directa a las grandes ciudades y a los entes locales intermedios.

De este modo el Comité de Expertos se configura como el verdadero órgano de garantía de los entes locales, los cuales son los titulares directos de los derechos reconocidos en la Carta.

En cuanto a las funciones del Comité de Expertos, pueden señalarse como posibles las siguientes:

\footnotetext{
5 Recogemos en parte las ideas contenidas en la Resolución de la CPLRE 223 (1991) «Sur le role des autorités locales et régionales dans la politique d'intégration entre l'Europe occidentale et orientale», apartado 16.
} 
CRONICAS

1. Emitir a instancia de parte legitimada un Informe sobre un Proyecto de texto normativo o sobre un texto normativo en vigor, analizando la adecuación o no del mismo a la Carta.

Para proceder a este "juicio de constitucionalidad" se arbitraría un procedimiento en dos fases. En la primera se acordaría la admisión o no de la petición en razón al objeto de la pretensión. En la segunda, admitida la «demanda», se emitiría el Informe razonado.

Una vez evacuado el Informe se dará conocimiento del mismo a la parte que lo solicitó, al Estado afectado y al Comité de Ministros.

2. Emitir un Informe anual valorando globalmente la actitud de los Estados en función de los casos que se hayan examinado a lo largo del año.

Obviamente estos Informes y recomendaciones no tienen otra fuerza que la que logre insertarles la "auctoritas» del Comité de Expertos. Pero si se consigue crear un Comité respetado por su propia competencia, los Informes que emita, en manos de los sujetos legitimados para obtenerlos, pueden llegar a constituir un precioso elemento para dar eficacia interna a los principios de la Carta, imponiendo su contenido sobre los poderes legislativo, ejecutivo y judicial. Se puede conseguir así un mecanismo para garantizar eficazmente el contenido de la CEAL, alcanzando el objetivo último de hacer de la misma la Constitución supranacional de la autonomía local.

La diferencia esencial entre los dos Comités propuestos es que mientras que el Comité permanente responde a la idea de un Comité de apoyo a los Estados, para asesorarles en el proceso interno de aplicación de la Carta, actuando por tanto a petición de los mismos o a través de la documentación que éstos le faciliten, el Comité de expertos trata de constituirse como un órgano al servicio de los intereses de los entes locales, y por tanto como órgano que pueda fiscalizar a instancia de parte interesada el cumplimiento interno del contenido de la Carta. Ciertamente este mecanismo de control tiene el límite de la debilidad de la medida que pueda adoptar (emitir un Informe de denuncia), pero como se ha dicho anteriormente, la propia importancia que adquiera el Comité de expertos puede terminar por dar a sus Informes una relevancia interna destacada, tanto por su influencia en las discusiones políticas, como por el papel que puede jugar en los procesos judiciales internos actuando como regla interpretativa del derecho estatal o autonómico. 


\section{CONCLUSIONES DE LA CONFERENCIA SOBRE LA CARTA EUROPEA DE AUTONOMIA LOCAL (BARCELONA, 23-25 DE ENERO DE 1992)}

1. Los participantes en la primera Conferencia sobre la Carta Europea de Autonomía Local, reunida en Barcelona del 23 al 25 de Enero de 1992, agradecen:

- a la ciudad de Barcelona su invitación como sede de la Conferencia y su hospitalidad en el transcurso de la misma.

- al Consejo de Europa, y en particular a su Conferencia Permanente de Poderes Locales y Regionales de Europa, su iniciativa de organizarla.

- al Consejo General del Poder Judicial su participación activa y su relevante contribución a la misma.

- a las demás instituciones y asociaciones que han cooperado en su organización, su apoyo y colaboración.

2. Consideran que la Carta Europea de Autonomía Local garantiza los fundamentos de la democracia local, determina los principios rectores para el desarrollo de la autonomía local, y contribuye así a la consolidación de la democracia y de los derechos humanos.

3. Manifiestan su satisfacción por el papel desempeñado por la Carta al proporcionar normas de referencia europeas para la instauración de sistemas democráticos de autonomía local en los países de Europa central y del este.

4. Se felicitan por el incremento considerable del número de Estados que han firmado o ratificado la Carta y, deseando que este número continúe aumentando, sobre todo entre los nuevos Estados miembros del Consejo de Europa, ruegan a aquellos que todavía no lo hubieran hecho que firmen o ratifiquen la Carta de Autonomía Local.

5. Se felicitan por el hecho de que la Carta haya inspirado las declaraciones sobre la autonomía local elaboradas sobre un ámbito geográfico más amplio por otras organizaciones, tales como la Unión Internacional de Autoridades Locales (IULA) y la Organización Ibero-americana de Cooperación Intermunicipal (OICI).

6. Consideran que, cualquiera que sea el sistema constitucional de los Estados para la aplicación de los tratados internacionales, las 
CRONICAS

disposiciones la de Carta libremente aceptadas por los mismos deberían ser escrupulosamente respetadas y tener un valor jurídico superior, en particular en aquellos Estados en que los tratados internacionales son fuente normativa de derecho interno.

7. Constatan que la legislación de los Estados que han ratificado la Carta, como también la de algunos otros Estados, respeta, en general, sus disposiciones. En muchos de ellos, sin embargo, se presentan problemas cuando se trata de aplicar los siguientes artículos:

- artículo 4, sobre el alcance de la autonomía local, que no debería restringirse por la adopción de leyes sectoriales o por procesos de centralización.

- artículo 6, sobre la adecuación de las estructuras y de los recursos administrativos a los cometidos de las entidades locales, que implica que disposiciones nacionales no puedan coartar la libertad de las mismas en la contratación y gestión de su propio personal de la manera que juzguen más conveniente.

- artículo 8, sobre el control administrativo de los actos de las entidades locales, que no debería afectar ni a la libertad ni a la eficacia de acción de los poderes locales.

- artículo 9, sobre los recursos financieros de las entidades locales, cuya insuficiencia comprometería a la misma autonomía local.

- artículo 11, sobre la protección legal de la autonomía local, que implica la necesidad de posibles recursos jurisdiccionales en caso de agresión a los principios de la autonomía local, tanto si es el resultado de una disposición legislativa o reglamentaria.

8. Consideran que un auténtico sistema de democracia local implica, de conformidad con los artículos 3.2 y 4.3 de la Carta, que las entidades locales más próximas al ciudadano y cuyos órganos son elegidos por sufragio universal, tendrían que disponer del máximo de competencias.

9. Constatan que las competencias locales pueden verse afectadas por la redistribución de competencias en el proceso de integración europea y estiman por ello indispensable que los principios de autonomía enunciados en la Carta sean reconocidos en los textos fundamentales de la Comunidad Europea. En consecuencia, piden a la CPLRE que inste, en 
colaboración con el Comité Regional de la Comunidad Europea recientemente constituído, y por todos los medios posibles, el reconocimiento y la puesta en marcha de la Carta y sus principios en el seno de la Comunidad Europea y su legislación.

10. Consideran que un sistema eficaz de democracia local y el respeto a la autonomía local implican la participación de entidades locales en la elaboración de las políticas y legislaciones internas que afectan a sus competencias.

11. Recuerdan que en la mayor parte de los Estados los tribunales constituyen, en caso de litigio, la última instancia de decisión e interpretación de la noción y de los principios de la autonomía local, pero que su jurisprudencia raramente se sustenta en la Carta Europea de Autonomía Local y en sus prescripciones.

12. Piden, en consecuencia, que se adopten medidas apropiadas para informar a las instancias judiciales competentes en los Estados miembros del Consejo de Europa y en particular a las de los Estados que han ratificado la Carta, para que tengan más en cuenta las disposiciones de la Carta en su jurisprudencia. Asimismo, sería conveniente que las entidades locales, en los procedimientos referidos a la afirmación de su autonomía, invocaran más a menudo la Carta Europea de Autonomía Local.

13. Estiman que sería conveniente establecer un sistema que permitiera el seguimiento de la Carta en los distintos países que la han ratificado.

14. Consideran que este sistema, a falta de una jurisdicción internacional, podría consistir en la creación de un comité el cual las partes contratantes someterían informes periódicos sobre la aplicación de la Carta: un mecanismo de esta naturaleza permitiría, en efecto, apreciar cómo se aplica la Carta en cada Estado, además de subrayar los casos eventuales en que la legislación nacional se aparta de ella.

Ahora bien, la naturaleza de los compromisos contenidos en la Carta, la gran diversidad de formas de democracia local existentes en los diferentes países, así como la complejidad y las demoras inherentes a la redacción de los informes, aconsejan una cierta prudencia en la aceptación de una solución de esta naturaleza.

15. Sugieren, como alternativa al sistema mencionado anteriormente y conforme a las ideas contenidas en el informe explicativo de la Carta Europea de Autonomía Local que la Conferencia Permanente de 
CRONICAS

Poderes Locales y Regionales de Europa, en el marco de sus responsabilidades políticas, debería poner en marcha un sistema propio para procurar que sean respetados los compromisos adquiridos en virtud de la Carta. A este respecto, la opinión general es la que la CPLRE podría escoger cada año cierto número de artículos de la Carta y obtener, por diferentes medios, incluido la consulta a expertos, informaciones sobre su aplicación en los Estados: sobre la base de una evaluación de los informes recibidos, la CPLRE podría formular propuestas a los gobiernos, a fin de promover la autonomía local.

16. Piden a la CPLRE el estudio de los problemas específicos de determinadas entidades locales, a fin de examinar si su dimensión justifica una concepción diversificada de la autonomía local. 
REAL-1992, núm. 255-256. TORNOS MAS, JOAQUIN. CONFERENCIA SOBRE LA CARTA EUROPEA...

REAL-1992, núm. 255-256. TORNOS MAS, JOAQUIN. CONFERENCIA SOBRE LA CARTA EUROPEA... 